\title{
Soundness assessment of structural timber elements in traditional timber dwellings: the combined use of quantitative IR thermograhy and ultrasonic testing
}

\author{
by A. Kandemir-Yücel ${ }^{*}$, A. Tavukçuoğlü ${ }^{* *}$ E. N. Caner-Saltık***
}

* Ministry of Culture and Tourism, Atatürk Bulvarı No:29, 06050, Ankara, Turkey, aysenur2000@hotmail.com

** Graduate Program in Building Science \& Materials Conservation Laboratory, Dept. of Architecture, Middle East Technical University (METU), Inonu Bulvari, 06800, Ankara, Turkey, aysetavukcuoglu@yahoo.com

*** Graduate Program in Restoration \& Materials Conservation Laboratory, Dept. of Architecture, METU, Inonu Bulvari, 06800, Ankara, Turkey, canersal@yahoo.com.tr

\begin{abstract}
The study was focused on the in-situ soundness assessment of structural timber elements in traditional timber dwellings by the combined use of quantitative IR thermography (QIRT) and ultrasonic testing. The laboratory QIRT and ultrasonic measurements were done to establish reference data on control samples, composed of sound and deteriorated historic and new timber samples, for the correct interpretation of in-situ QIRT and ultrasonic data. By ultrasonic testing, precise knowledge was obtained on mechanical properties of timber on quantitative basis. That knowledge was necessary for the QIRT analyses to define the thermal inertia characteristics of timber elements in relation to their state of deterioration. The data results also allowed discussing the compatibility criteria for timber elements and neighbouring materials in contact with them.
\end{abstract}

\section{Introduction (Arial, 9pt, bold)}

The unnecessary renewing of historic/old timber with young/new one is the common mistake of recent repairs. The inherent mechanical properties and the abundance of extractives protecting the timber against insects make the old timber more durable and superior to the new one [1,2]. Therefore, any intervention on timber should be planned following a comprehensive in-situ examination, preferably without giving any damage to the structure. The NDT methods, such as IR thermography (IRT) and ultrasonic pulse velocity (UPV) measurements, are promising tools to assess the state of deterioration for timber elements, compatibility of neighbouring materials and appropriateness of the boundary conditions for them [3-5]. The advancement of NDT methods and their use on site, therefore, is a necessity for the preservation of historic elements keeping the architectural and technological authenticity of historic structures.

\section{Material and Method}

The study was conducted on two $19^{\text {th }}$ century traditional timber dwellings in Ankara (figure 1). Those houses were composed of mudbrick masonry at the ground floor and timber frame structure at the upper level. The mudbrick masonry was supported by timber bond beams while the timber frame upper structure consisted of timber studs, joists, lintels and bracings together with mudbrick and fired brick infill. The timber post and beam elements as well as neighbouring fired brick and mudbrick infill at Ayaş and Istiklal Houses were examined in-situ by QIRT and UPV measurements. Those in-situ studies were supported by laboratory analyses composed of QIRT and ultrasonic testing. Some control samples of structural timber, brick, mudbrick infill and plaster were collected from those houses to establish reference data at laboratory for better interpretation of in-situ measurements.
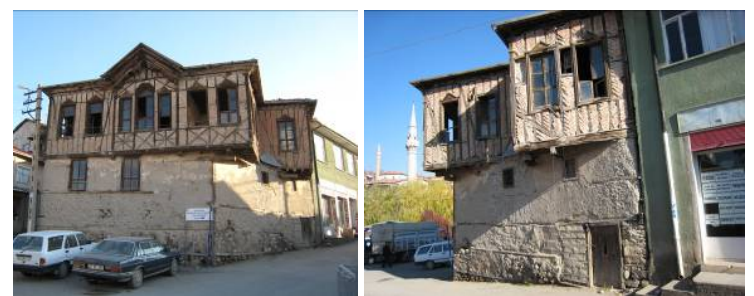

Fig.1. Front and side views of Ayaş House (at the left) and Istiklal House (at the right).

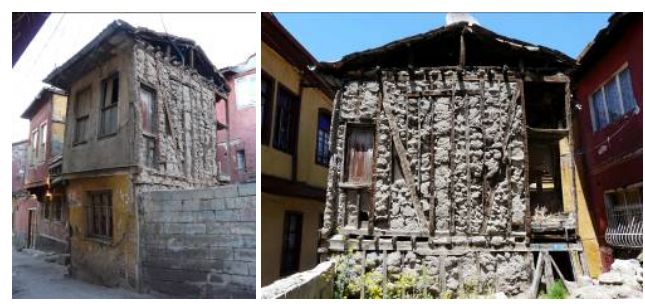

The QIRT survey was done by single and sequential IR imaging. The sequential IR imaging was conducted on interior and exterior surfaces of the houses under examination as well as the control samples at the laboratory. The sequential IR imaging in-situ was carried out by taking infrared images in series at 2-10 seconds intervals in daytime and at night for a period of 5-10 minutes during the heating or cooling conditions. The IR images were taken by using the "ThermoCAM SC640" thermographic equipment. The additional heating source, halogen lamp providing maximum output of 650 Watts, was used at laboratory to heat up the control samples. Thermal response characteristics of timber and its traditional neighbouring materials were examined by producing the graphs showing surface temperature, $T$, and temperature difference, $\Delta T$, as a function of square root of time. The slope of the linear regression presented the rate of warming up, $R_{W}$, or the rate of cooling down, $R_{C}$, for each control sample or target area on site. The comparative value representing the ratio of thermal response characteristics of the target area to the neighbouring sound timber sample was calculated to discuss the soundness state and compatibility issue for those materials.

The ultrasonic measurements were carried out in order to determine the mechanical properties of timber in terms of ultrasonic pulse velocity (UPV) and modulus of elasticity (MoE). The mechanical strength of in-situ timber elements, such as posts and beams, was assessed by comparing their in-situ UPV data with the reference UPV data obtained at laboratory. That knowledge was then used to define thermal behaviour of timber elements in relation to their state of deterioration. UPV measurements were done both in direct transmission (cross direction) and indirect transmission mode (parallel to surface) by using a portable PUNDIT PLUS CNS FARNELL instrument with $220 \mathrm{kHz}$ transducers. The anisotropic characteristics of timber were considered during the UPV measurements. 


\section{Results and Discussion}

The combined interpretation of the in situ and laboratory analyses was done to assess the soundness of structural timber elements in terms of ultrasonic and thermal inertia characteristics and to define the healthy boundary conditions for timber in relation to the dampness problems and incompatible repairs.

UPV data reflected the differences in physico mechanical properties of timber in relation to fiber direction (figure 2). Direct UPV data parallel to fiber direction were found to be considerably higher than the ones perpendicular to fiber direction. Indirect measurements were much lower than the direct ones with the ratio of 0.32 in average.

Fig.2. The UPV L-DIRECT and UPVR-DIRECT values of the control timber samples collected from traditional houses (at the left); and their UPV INDIRECT and MoE $E_{L-I N D I R E C T}$ values (at the right).
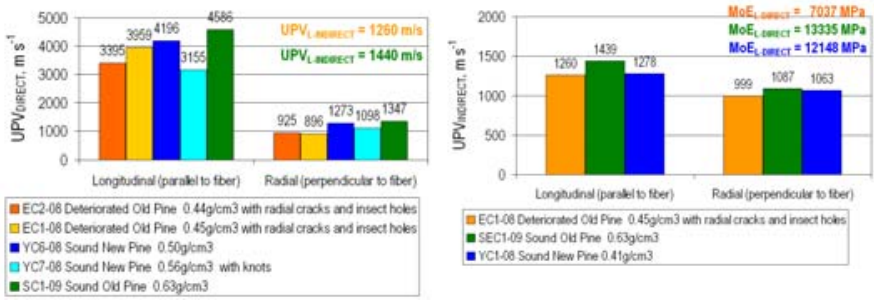

For dry sound timbers, the differences in their rate of heating and cooling were mainly due to the differences in their density. QIRT allowed differentiating the sound and deteriorated timber as well as their species due to the differences in their thermal properties. The deteriorated and sound pine timbers could be clearly distinguished from each other due to the lower thermal inertia characteristics of the deteriorated one corresponding to the faster rates of warming up and cooling down.
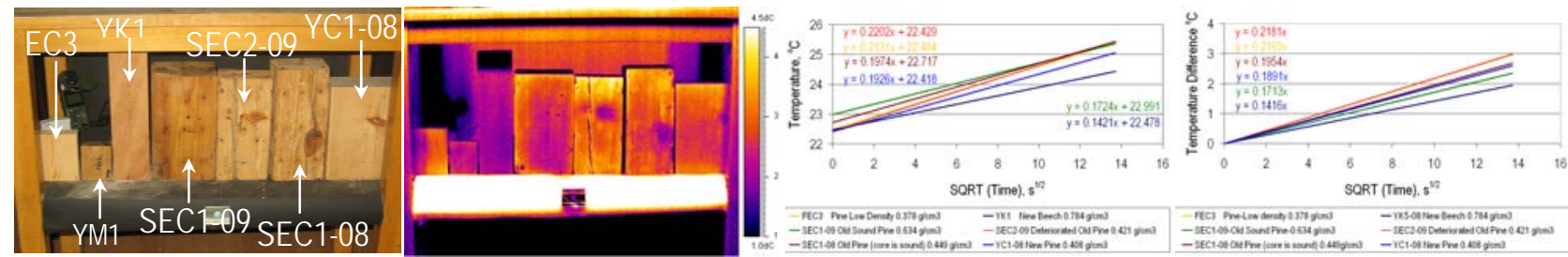

Fig.3. View of control samples, differential IR image produced from the IR sequence taken for the heating period of $324 \mathrm{~s}$, the linear fitting of surface temperatures and temperature differences versus square root of time for that period.

In-situ indirect UPV measurements of this study, has assured the soundness of timber elements in some parts and extensive deterioration in other parts (figure 4). Those parts were used as reference areas in QIRT measurements and their thermal inertia characteristics were determined (figure 4). Compatibility relationship between timber and neighbouring materials could be well demonstrated by the ratios of their warming or cooling rates compared to the sound timber. Similar thermal inertia characteristics of timber elements and mudbrick infill signaled that they were compatible with each other.
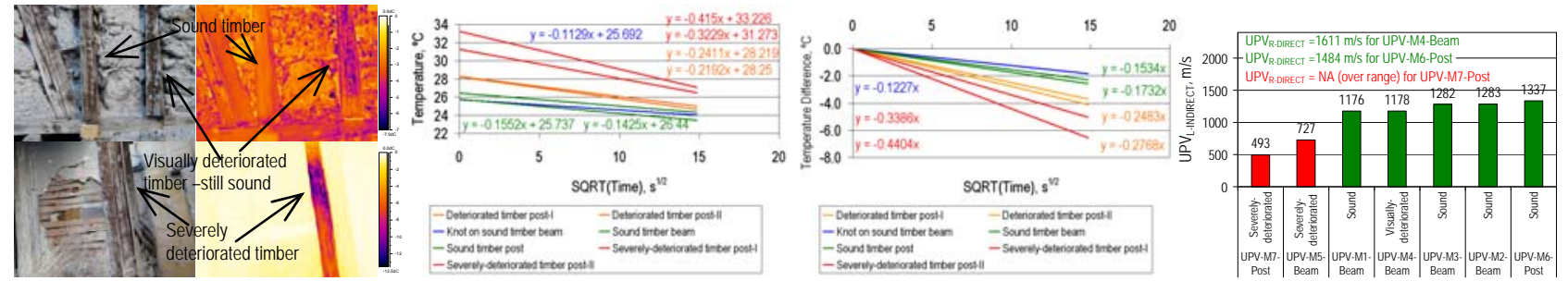

Fig.4. Partial views of Istiklal House timber elements and their differential IR images (at the left); the rates of cooling down for each timber element (at the middle); UPV values of sound and deteriorated post and beam elements taken parallel to fiber direction in indirect transmission mode (at the right).

\section{Conclusion}

The joint use of QIRT and UPV methods on site combined with laboratory analyses allowed to assess the state of deterioration for structural timber elements, to evaluate healthy boundary conditions with the neighbouring materials of timber and build up the urgent and long-term conservation programs.

\section{REFERENCES}

[1] Ridout, B. Timber Decay in Buildings, The Conservation Approach to Treatment. London and Newyork: Spon Press, 2001.

[2] Rug, W., Seemann, A., "NDT Strength of Old Timber, Test Cores From 50-400 Years Old Timber Indicates Strength of Old Timbers Corresponds to that of New", Building Research and Information, 1991, 19, 1, 31-37.

[3] Kandemir Yucel, A., Tavukcuoglu, A., Saltik, E. N. In Situ Assessment of Structural Timber Elements of a Historic building by Infrared Thermography and Ultrasonic Velocity. Infrared Physics \& Technology, 2007, 49, $243-248$.

[4] Ludwig, N., Redaelli, V., Rosina, E., Augelli, F. Moisture detection in wood and plaster by IR thermography, Infrared Physics and Technology, 2004, 46, 161-166.

[5] Grinzato, E., Bressan, C., Marinetti, S., Bison, P.G. \& Bonacina, C. Monitoring of the Scrovegni Chapel by IR thermography: Giotto at infrared. Infrared Physics \& Technology, 2002, 43, 165-169. 